$\mathbb{T}$ periodica polytechnica

Transportation Engineering

41/2 (2013) 123,126

doi: 10.3311/PPtr.7112

http://periodicapolytechnica.org/tr

Creative Commons Attribution (1)

RESEARCH ARTICLE

\section{Alloying Effects on Wetting Ability of Diluted Cu-Sn Melts on Graphite Substrates}

Illés Salacz / Zoltán Weltsch

Received 2013-09-04

\begin{abstract}
The wettability of graphite by the copper-tin (Cu-Sn) liquid alloy was measured using the sessile drop method at a temperature interval of 1273-1473 K. The system is found poorly wetting with the contact angle at an interval of 115... 143 degrees. The concentration dependence of contact angle $(\Theta)$ exhibits similar trends, than the residual resistivity change measured in the same alloys in solid state. The solid solution of $\mathrm{Cu}$-Sn has a huge effect to the wetting ability, which was measured liquid phase beyond the liquidus.
\end{abstract}

\section{Keywords}

wetting $\cdot$ contact angle $\cdot$ copper $\cdot$ tin $\cdot$ solid solution

\section{Acknowledgement}

This work has been supported by the Hungarian Scientific Research Fund (OTKA) through grant No. K-73690.

\section{Illés Salacz}

Department of Automobiles and Vehicle Manufacturing, Budapest University of Technology and Economics, Bertalan L. u. 2., H-1111 Budapest, Hungary e-mail: illes.salacz@gmail.com

\section{Zoltán Weltsch}

Department of Automobiles and Vehicle Manufacturing, Budapest University of Technology and Economics, Bertalan L. u. 2., H-1111 Budapest, Hungary e-mail: weltsch@kgtt.bme.hu

\section{Introduction}

The $\mathrm{Cu}$ based alloys are widely used in various brazing and welding techniques. One of the perspective families of lead-free solder alloy systems is based on the $\mathrm{Cu}$-Sn binary alloy (Amore et al. [1,2]; Chen [3]; Hlinka [4]; Lénárt [9]). Ensuring the good wetting conditions between the solder material and the metallic parts to be joined is of great importance in these processes (Qiulian et al. [5]). The magnitude of contact angle between the liquids and solid substances represents the quantitative measure of the wetting ability.

In the present paper, experimental results will be presented for the concentration dependence of the wettability of graphite by the liquid Ag-Sn alloy. Not only the wetting angle, but the slope of temperature dependence $\Theta(\Delta T)$ were compared on graphite substrate. The results were interpreted on the basis of classic alloying effects, i.e. based on the change in alloy (Sn) concentration.

\section{Experimental}

Alloys were prepared from high purity (4N) $\mathrm{Cu}$ and $\mathrm{Sn}$, using induction melting in quartz crucible under inert (Ar) atmosphere. The stability range of these $\alpha$-terminal solid solutions of $\mathrm{CuSn}$ shows the Fig. 1, with marked the investigated alloy composition $\left(\mathrm{Cu}, \mathrm{Cu}_{97} \mathrm{Sn}_{3}, \mathrm{Cu}_{95} \mathrm{Sn}_{5}, \mathrm{Cu}_{90} \mathrm{Sn}_{10}\right)$. The $\mathrm{Cu}_{97} \mathrm{Sn}_{3}$, $\mathrm{Cu}_{95} \mathrm{Sn}_{5}$ alloy pass the solid solution range, the $\mathrm{Cu}_{90} \mathrm{Sn}_{10}$ alloy just out of this region.

The graphite substrate was prepared from high purity, porosity free base material. The substrates were mechanically polished, then the surface roughness was determined using a 3D laser profilometer. (Rodenstock RM600 surface topography measurement system).

Wetting experiments were performed in a sessile drop equipment following the method described in Ref. (Satyanarayan [6]). The graphite substrate and the alloy pieces were positioned into the middle of furnace at ambient conditions. The pressure was then reduced to $0.1 \mathrm{~Pa}$ at room temperature in the chamber. The vacuum was replaced by a $105 \mathrm{~Pa} 99.999 \% \mathrm{Ar}$ gas. This procedure was repeated 3 times. Subsequently, the temperature was raised to $1273 \mathrm{~K}$ using a heating rate of $4 \mathrm{~K} / \mathrm{s}$. 
Since only a small portion of the gas chamber is heated, the pressure around the droplet remains at about $105 \mathrm{~Pa}$ during the run of measurements, which were performed at 1373, 1423 and $1473 \mathrm{~K}$ respectively.

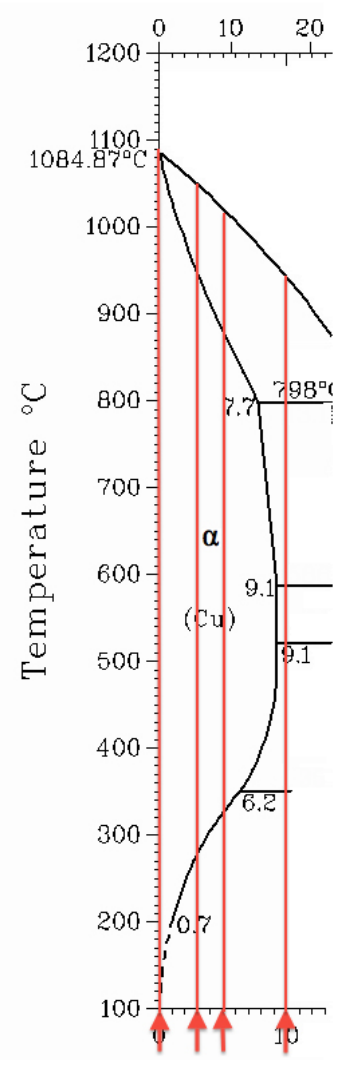

Fig. 1. The range of terminal $(\alpha)$-solid solutions in $\mathrm{Cu}-\mathrm{Sn}$ system

During the measuring run (with increasing temperature) the heating power has stopped around each measuring temperature. The equilibrium contact angle is stabilized within one minute (Weltsch et al. [7]). Two minutes holding time was applied before the measurement.

The contact angle was directly measuring the profile of the drop, fixing and processing the data, using self-made automatic evaluation software in the Matlab environment. Though the uncertainty of this software is below 1 degree, the total uncertainty of the measured values is: $\pm 3^{\circ}$.

After the measuring process at $1473 \mathrm{~K}$, the furnace was switched off and cooled slowly to the ambient temperature (the whole cooling time is around 40 minutes). Subsequently the furnace was opened and the solidified sample was removed.

\section{Results}

The final contact angle is affected by several circumstances. The two strongest from them are the oxidation and the surface roughness of the substrates. It should be emphasized that the most important parameter to compare the details from the literature are the properties of the substrate, especially the material and its surface roughness.

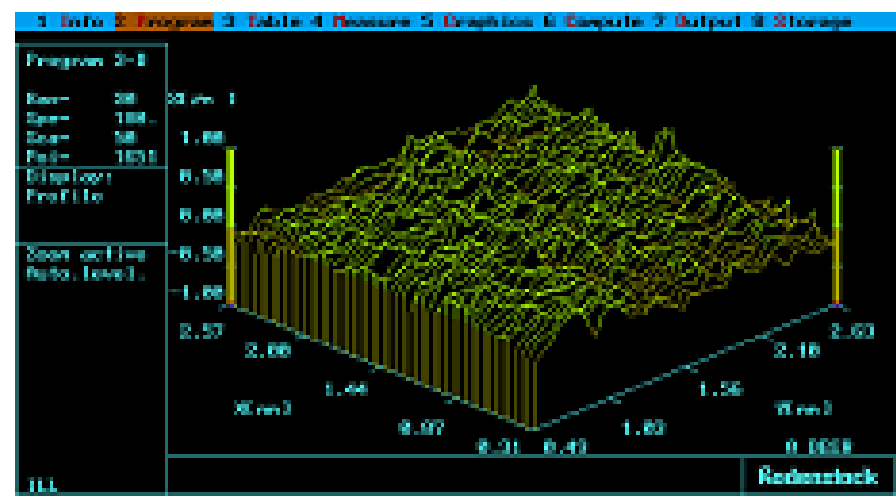

Fig. 2. Graphite substrate surface topography picture

The substrates surface roughnesses have a profound and technologically important influence on the behavior of wetting fluids. One of the first studies about the effects of surface roughness on the equilibrium contact angle $\Theta_{0}$, between wetting liquid and solid substrate was reported by Wenzel (Wenzel [8]). He claimed that surfaces what wet with an angle $\Theta_{0}<90^{\circ}$ then if it is smooth it will wet even better if rough. Conversely, he argued that if the smooth surface does not wet well, the rough surface is worse. This behavior is expressed in the relationship:

$$
\cos \Theta_{r}=r \cdot \cos \Theta_{0}
$$

where $\Theta_{r}$ is the contact angle on a surface with roughness ratio, $r$, given by the ratio of actual wetted surface area to geometric or projected area. According to (1), the roughness of a surface further decreases the contact angle if $\Theta_{0}<90^{\circ}$, whereas the roughness further increases the contact angle if $\Theta_{0}>90^{\circ}$.

Roughness parameters included:

$\mathrm{Ra}$ the arithmetical mean line to a roughness profile

$\lambda$ the main horizontal wavelength

$r$ defined as the ratio of the true area of the solid surface to the apparent area

The tested area was $10^{-4} \mathrm{~m}^{2}$ and the roughness measurement was repeated 5 times. The measured roughness parameters are shown in Fig. 2 and Tab. 1 .

Tab. 1. Roughness parameters of the $\mathrm{C}$ substrate

\begin{tabular}{llll}
\hline Material of the substrate & $R a[\mu \mathrm{m}]$ & $\lambda[\mu \mathrm{m}]$ & $r[-]$ \\
\hline $\mathrm{C}$ & $0.238 \pm 0.007$ & $17.02 \pm 0.52$ & $1.006 \pm 0.001$ \\
\hline
\end{tabular}

The weight and the volume reduce during the measurement cause changes in the contact angle. To determine the degree of the change in the weight of the melt droplet was measured before and after the measurement. Tab. 2 includes all the weight data for alloys in the $\alpha$-phase.

It can be seen that the mass of the out steamed metal has a minimal value, in average the weight reduction is $0.000125 \mathrm{~g}$ that is $\sim 0.070003 \%$ of the weight of the sample. This very 
Tab. 2. The change of the samples mass

\begin{tabular}{lllll}
\hline Combination & $\begin{array}{l}\text { Weight before } \\
\text { measurement [g] }\end{array}$ & $\begin{array}{l}\text { Weight after } \\
\text { measurement [g] }\end{array}$ & $\begin{array}{l}\text { Weight } \\
\text { reduction [g] }\end{array}$ & $\begin{array}{l}\text { Weight } \\
\text { reduction [\%] }\end{array}$ \\
\hline $\mathrm{Cu}$ & 0.2370 & 0.2369 & 0.0001 & 0.0421 \\
$\mathrm{Cu}_{97} \mathrm{Sn}_{3}$ & 0.2395 & 0.2394 & 0.0001 & 0.0417 \\
$\mathrm{Cu}_{95} \mathrm{Sn}_{5}$ & 0.2377 & 0.2374 & 0.0003 & 0.126 \\
$\mathrm{Cu}_{90} \mathrm{Sn}_{10}$ & 0.2378 & 0.2373 & 0.0005 & 0.0021 \\
\hline
\end{tabular}

small amount of the material is approximately $0.012 \mathrm{~mm}^{3}$ volume reduction that effects about $0.005-0.01^{\circ}$ difference. It is not a considerable value, so it is negligible.

The wetting analysis of the properties of the melted drop is based on a graphite substrate therefore the exact details are not appropriate to compare them with other substrates. This research is focused on analysis of the copper solid phase. Two alloys are in this phase $\left(\mathrm{Cu}_{97} \mathrm{Sn}_{3}, \mathrm{Cu}_{95} \mathrm{Sn}_{5}\right)$, so $\mathrm{Cu}$ is one reference and $\mathrm{Cu}_{90} \mathrm{Sn}_{10}$ is the other reference outside of the $\alpha$-phase. It is important to focus on the change at a phase changing boarder (9.1\% Sn content). In this case we observe the effect by systematically changing the electronic structure with changing the combining content (Sn).

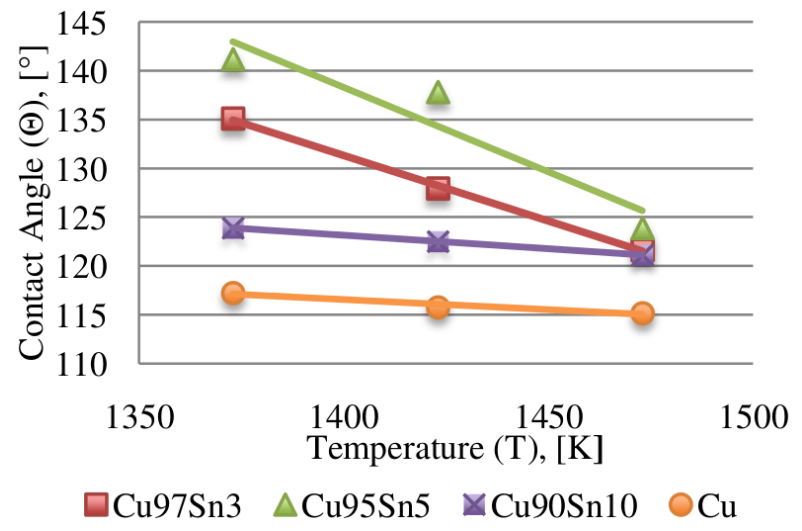

Fig. 3. The temperature dependence of the wetting angle of pure $\mathrm{Cu}$, and $\mathrm{Cu}$ alloyed with $3,5,10$, at.\% of Sn on graphite substrate

Fig. 3 includes the result of the measuring. It can be seen that points belong to one composition are linked together with a straight line. Based on the Eötvös-rule wetting angles are changing linearly if the temperature is increasing. When looking at the results it is visible that the temperature dependence is very low for $\mathrm{Cu}$. By increasing the combining material with only $3 \%$ of $\mathrm{Sn}$, the value of the contact angle changes a lot and the temperature dependence is much greater. The same phenomenon appears in the case of $\mathrm{Cu}_{95} \mathrm{Sn}_{5}$ where the highest value of the contact angle is reached and this material has the worst wetting proper in our search. $\mathrm{Cu}_{90} \mathrm{Sn}_{10}$ is the next of the $\alpha$-phase and as it seems, the value of the temperature dependence is quite lower and the values of the contact angle are also lower. The alloy includes only $0.9 \%$ extra tin but the effect is outstanding. The values of the contact angle are higher than in the case of the unalloyed copper, but comparing them at $1373 \mathrm{~K}$ the difference is significant.

By increasing the combining content systematically, changes of the electronic structure cause huge differences in many properties even if they are in the same phase. It seems that clear copper has the best wetting properties at every temperature and by increasing the combining content the wetting properties deteriorate.

\section{Summary}

Knowledge of the wetting properties is essential for applied advanced vehicle materials and for using the most innovative manufacturing technologies. Because of the continuously increasing amount of binding joints as in the field of automotive industry or in the electronics industry, the demand is very high against them, while on the other hand the main need is price and the lowest weight as possible. It is crucial to know the standard wetting properties of brazing alloys for designing the combination of the contents. There are also several affecting factors that are also important to know the exact effect what they cause.

Analyzing $\mathrm{Cu}-\mathrm{Sn}$ wetting properties the results showed that as a pure substance the contact angle has a lower value than combining them to each other. In the case of low content of alloying metals, above the solid solution range, large-scale change can be experienced; the wetting properties become worse and the temperature dependence increases. Due to the evaporation of raw materials it is considerably low enough to disregard them so it cannot affects the slope of the linear regression lines. The contact angle values are comparable because the departing amounts of material do not significantly influence the change.

The slope, i.e. the rate of change of the wetting ability function of the temperature showed that next to the liquidus line the wetting properties of the melt phase are apparently influenced by the texture under the liquidus.

The experiment also showed that the more we move away from the liquidus the Eötvös-rule applies less.

\section{References}

1 Amore S, Ricci E, Borzone G, Novakovic R, Wetting behaviour of leadfree Sn-based alloys on $\mathrm{Cu}$ and Ni substrates, Materials Science and Engineering: A, 495(1), (2008), 108-112, DOI $10.1016 /$ j.msea.2007.10.110

2 Amore S, Ricci E, Lanata T, Novakovic R, Surface tension and wetting behaviour of molten $\mathrm{Cu}-\mathrm{Sn}$ alloys, Journal of Alloys and Compounds, 452(1), (2008), 161-166, DOI $10.1016 /$ j.jallcom.2007.01.178

3 Chen W, Xue S, Wang H, Wetting properties and interfacial microstructures of $S n-Z n-x G a$ solders on Cu substrate, Materials \& Design, 31(4), (2011), 2196-2200, DOI 10.1016/j.matdes.2009.10.053

4 Hlinka J, Weltsch Z, Berzy J, Szmejkál A, Impovements of Sessile Drop Method for the Wetting Angle Determination, Perner's Contact, Special 2, 6, (2011), 64-71. 
5 Qiulian Z, Jianjun G, Xiaolong G, Xinbing Z, Xiaogang L, Wetting Behaviors and Interfacial Reaction between Sn-10Sb-5Cu High Temperature Lead-free Solder and Cu Substrate, Journal of Materials Science \& Technology, 26(2), (2010), 156-162, DOI 10.1016/S1005-0302(10)60026-6

6 Satyanarayan S, Prabhu KN, Reactive wetting, evolution of interfacial and bulk IMCs and their effect on mechanical properties of eutectic $\mathrm{Sn}-\mathrm{Cu}$ solder alloy, Advances in Colloid and Interface Science, 166(1-2), (2011), 87-118, DOI $10.1016 /$ j.cis.2011.05.005

7 Weltsch Z, et al., Measurement and modeling of the wettability of graphite by a silver-tin (Ag-Sn) liquid alloy, Applied Surface Science, 268, (2013), 52-60, DOI $10.1016 / \mathrm{j}$.apsusc.2012.11.150

8 Wenzel RN, Resistance of solid surfaces to wetting by water, Industrial \& Engineering Chemistry, 28(8), (1936), 988-994, DOI 10.1021/ie50320a024

9 Lénárt B, Automatic identification of ARIMA models with neural network, Period Polytechnica Transportation Engineering, 39(1), (2011), 39-42, DOI 10.3311/pp.tr.2011-1.07 